\title{
USO ENERGÉTICO DE RESÍDUOS MADEIREIROS NA PRODUÇÃO DE CERÂMICAS NO ESTADO DE SÃO PAULO
}

\author{
ENERGY USE OF WOOD RESIDUES IN PRODUCTION OF CERAMICS IN THE STATE OF \\ SAO PAULO
}

Guilherme de Andrade Lopes ${ }^{1}$ José Otávio Brito ${ }^{2}$ Luiz Fernando de Moura ${ }^{3}$

\begin{abstract}
RESUMO
O uso da biomassa florestal é uma importante alternativa de fonte energética renovável, econômica, técnica e ambientalmente viável, disputando espaço com outras fontes energéticas, mais caras ou não renováveis, tais como gás natural, óleo diesel e GLP. Dentro do setor industrial, maior consumidor de energia a partir de biomassa, destaca-se o segmento de cerâmicas vermelhas, tradicional consumidor de lenha para a produção de energia. Uma considerável parcela de empresas deste setor recentemente passou a utilizar, como alternativa de energia, cavacos produzidos a partir de resíduos madeireiros diversos. A opção por esse tipo de biomassa se deve a quatro principais razões: maior disponibilidade desse material para aquisição no mercado; envolver um importante aspecto ambiental, uma vez que se trata de um material de origem renovável; por proporcionar uma maior homogeneidade durante a combustão, quando comparado com a lenha; e possibilita a automação da alimentação dos fornos. O presente estudo teve por objetivo caracterizar e descrever o segmento de cerâmicas vermelhas no Estado de São Paulo quanto ao consumo de resíduos madeireiros para fins energéticos. A pesquisa por amostragem coletou dados regionais sobre a quantidade e eficiência do uso de resíduos madeireiros como fonte de geração de energia no setor, bem como aspectos tecnológicos, econômicos e logísticos associados ao uso desta biomassa. Estima-se que o uso de cavacos de madeira vem sendo adotado atualmente por cerca de $80 \%$ das cerâmicas de porte médio no Estado de São Paulo. Os cavacos são originados de resíduos de serrarias, operações da colheita florestal de pinus e eucalipto, poda de arborização urbana e reciclagem de produtos madeireiros em geral. O raio médio de distância para suprimento dos cavacos até as cerâmicas é de aproximadamente $200 \mathrm{~km}$. As cerâmicas avaliadas compram os cavacos de terceiros a um preço médio em torno de $\mathrm{R} \$ 43,00$ por $\mathrm{m}^{3}$. A eficiência média apurada foi de $1,4 \mathrm{~m}^{3}$ de cavaco para cada milheiro de peças acabadas produzidas. As cerâmicas expressaram a necessidade de maior regularidade na qualidade deste biocombustível, que normalmente varia a cada carga recebida.
\end{abstract}

Palavras-chave: energia; biomassa; bioenergia; mercado.

\begin{abstract}
The use of forest biomass is an important alternative source of renewable, economic, technical and environmentally viable energy, which struggles to displace other energy sources that are more expensive or non-renewable, such as natural gas, diesel oil and LPG. Within the industrial sector, which is the biggest consumer of energy from biomass, the red ceramics sector represents a traditional consumer of firewood for energy production. A considerable number of companies in this sector has recently started to use, as an
\end{abstract}

1 Engenheiro Florestal, Dr., Coordenador Sênior de Certificação Florestal, Instituto de Manejo e Certificação Florestal e Agrícola, Estrada Chico Mendes, 185, CEP 13426-420, Piracicaba (SP), Brasil. guilherme@imaflora.org

2 Engenheiro Florestal, Dr., Livre-Docente e Professor Titular do Departamento de Ciências Florestais, Universidade de São Paulo, Escola Superior de Agricultura “Luiz de Queiroz”, Av. Pádua Dias, 11, CEP 13418-900, Piracicaba (SP), Brasil.jobrito@usp.br

3 Engenheiro Florestal, Dr., Coordenador Técnico de Projetos, Plant Inteligência Ambiental Ltda, Rua Moraes Barros, 1413, CEP 13419-240, Piracicaba (SP), Brasil. luiz@plantbr.com.br

Recebido para publicação em 17/03/2014 e aceito em 5/09/2014 
alternative option for energy production, chips made from several different wood wastes. The choice for this type of biomass is due to four main reasons: high availability of material on the market; environmental benefits, since it is a renewable material; higher uniformity during combustion, compared with firewood; and feasibility for implementation of an automatic furnace feeding system. This study aimed to characterize and describe the red ceramics sector in the State of Sao Paulo, regarding the consumption of wood residues for energy purposes. The sampling survey collected regional data on the quantity and efficiency of use of wood residues as a source for energy generation in the sector, as well as on technological, economic and logistical aspects related to the use of this biomass. It is estimated that the use of wood chips is being presently adopted by approximately $80 \%$ of medium scale ceramic plants in the State of Sao Paulo. These chips are originated from sawmill residues, forest harvest operations of pine and eucalyptus, urban trees pruning and recycling of wood products in general. The average distance radius for supply of chips to the ceramic plants is approximately $200 \mathrm{~km}$. The evaluated ceramic plants outsource chips at an average price of $R \$ 43.00$ per $\mathrm{m}^{3}$. The average efficiency observed was of $1.4 \mathrm{~m}^{3}$ of chips per thousand finished pieces produced. The ceramic plants reported the need for a better regularity in quality of this bio-fuel, which usually varies for each other load delivered.

Keywords: energy; biomass; bioenergy; market.

\section{INTRODUÇÃO}

A biomassa é uma das alternativas mais promissoras para geração de energia renovável. A lenha foi a principal fonte de energia primária no Brasil por mais de 450 anos. Faz relativamente pouco tempo que ela deixou de ser a principal fonte de energia primária no país, quando, no século passado, ou mais exatamente durante a década de 1970, ela foi suplantada pelo petróleo e, em seguida, pela hidroeletricidade. A participação da madeira no balanço energético brasileiro veio decrescendo ao longo do tempo, sobretudo porque houve um incentivo maior para o uso de derivados de petróleo e hidroeletricidade, para atendimento das novas demandas energéticas (SÜFFERT; BAJAY; LIMA, 2005). Nos últimos dez anos, no entanto, pôdese constatar uma forte reversão nessa tendência. Isso talvez esteja sendo motivado pelas incertezas quando à oferta de outras fontes e, sobretudo, pelas vantagens econômicas e oportunidades ambientais e estratégicas oferecidas pelo uso da madeira como fonte de energia (BRITO, 2007). Assim, o aumento do interesse por parte de empresas, o apoio governamental e a expansão atual do uso de fontes energéticas renováveis é favorecido principalmente pelas vantagens ambientais por elas proporcionadas, quando comparadas com outras fontes consideradas não renováveis.

Dentre os principais setores consumidores de energia no país, destacam-se os setores industriais, com $36 \%$ do consumo total, e o de transportes, com $29 \%$ do consumo total. Dentro do setor industrial, o consumo energético é bem distribuído, sendo o maior consumidor o setor de produção de ferro gusa e aço, com 16,6 milhões de tep anuais $(19,4 \%)$. Merece destaque também os setores de papel e celulose, com 10 milhões de tep $(11,7 \%)$ e o de cerâmica, com 4,5 milhões de tep $(5,3 \%)$, que consome mais energia que o setor de cimento, 4 milhões de tep $(4,8 \%)$ (EMPRESA DE PESQUISA ENERGÉTICA, 2011).

Atualmente, a biomassa, principalmente bagaço de cana, carvão vegetal e madeira, representa cerca de $23 \%$ do total das fontes energéticas utilizadas no país. A madeira responde por cerca de $9 \%$ do total da matriz energética brasileira. No Brasil, no mínimo $50 \%$ da madeira utilizada têm destinação energética. Se essa quantidade de madeira para energia, no seu equivalente em toneladas de petróleo, for transformada em volume efetivo do produto, os valores seriam da ordem de 156 milhões de $\mathrm{m}^{3}$ anuais (BRITO et al., 2008). O Balanço Energético do Estado de São Paulo (BEESP) (SECRETARIA DE ENERGIA, 2011) aponta que a biomassa ocupa a segunda posição no consumo final energético estadual, com $25 \%$ do total, sendo que o petróleo e seus derivados ocupam a primeira posição, com $35,5 \%$, e a hidroeletricidade a terceira posição, com $20 \%$.

A madeira possui importante papel como fonte de energia ambientalmente mais saudável, o que a potencializa como alternativa aos combustíveis fósseis, resultando em diminuição das emissões dos gases do efeito estufa (BRITO, 2007), com potenciais incentivos provindos dos mercados 
internacionais de créditos de carbono. A biomassa também apresenta maior potencial para a geração de empregos no meio rural, além de disponibilidade de tecnologia já desenvolvida para a conversão em energia, com elevada eficiência.

A agroindústria e a indústria florestal, dentre elas a sucroalcooleira, papel e celulose e madeireira, são exemplos de setores que produzem resíduos com potencial importante de aproveitamento energético no Brasil. Outra importante fonte de biomassa utilizada atualmente para fins energéticos são os cavacos de madeira produzidos em usinas de reciclagem e que utilizam, como matériaprima, resíduos de madeira provenientes de aterros municipais ou da construção civil. Esses resíduos são coletados, processados e comercializados para empresas que necessitam de energia térmica para seus processos industriais, dentre elas, empresas do setor de cerâmicas.

O setor industrial da cerâmica é bastante diversificado e pode ser dividido nos seguintes segmentos: cerâmica vermelha, materiais de revestimento, refratários, louça sanitária, isoladores elétricos de porcelana, louça de mesa, cerâmica artística, filtros cerâmicos, cerâmica técnica e isolantes térmicos (SEBRAE, 2008). A cerâmica vermelha abrange um grupo de materiais cerâmicos constituído por tijolos, telhas, tubos, lajotas, vasos ornamentais, dentre outros, geralmente fabricados próximos dos centros consumidores, utilizando matérias-primas locais. As matérias-primas são argilas e siltes argilosos, com alto valor de impurezas, entre as quais se destacam minerais de ferro, responsáveis pela coloração vermelha típica dos produtos (BACCELLI JÚNIOR, 2010).

O setor de cerâmicas é um importante consumidor de madeira para energia no Brasil. De acordo com dados históricos do Ministério de Minas e Energia (MME), em 2010, a lenha foi responsável pela produção de $51 \%$ do total da energia consumida pelo setor de cerâmicas no Brasil, ou seja, aproximadamente 16,5 milhões de $\mathrm{m}^{3}$ de madeira a cada ano (EMPRESADE PESQUISA ENERGÉTICA, 2011). Anualmente, estima-se que o setor de cerâmica paulista consome aproximadamente 1 milhão de $\mathrm{m}^{3}$ de lenha para fins energéticos, havendo, portanto, uma grande oportunidade para inserção da biomassa na matriz energética destas indústrias no estado, que ainda utilizam gás natural (48\%), eletricidade $(24,5 \%)$, óleo diesel (8\%) e GLP (7\%) (SÃO PAULO, 2011).

A ANICER (Associação Nacional da Indústria Cerâmica) aponta que o mercado nacional conta com cerca de 5.500 empresas entre cerâmicas e olarias, sendo responsável por mais de $400 \mathrm{mil}$ empregos diretos, 1,25 milhões indiretos e gerando um faturamento anual de R\$ 6 bilhões $(4,8 \%$ do faturamento da indústria da construção civil) (ASSOCIAÇÃO NACIONAL DA INDÚSTRIA CERÂMICA, 2007). A ABC (Associação Brasileira de Cerâmica) contabiliza, especificamente para a cerâmica vermelha, a geração de 300 mil empregos, com faturamento anual da ordem de $\mathrm{R} \$ 2,8$ bilhões (ASSOCIAÇÃO BRASILEIRA DE CERÂMICAS, 2008).

O segmento da cerâmica vermelha é caracterizado pela existência de várias empresas pulverizadas no mercado nacional, em sua maioria, de micro, pequeno e médio portes (SEBRAE, 2008), que utilizam processos produtivos tradicionais, com base em tecnologias desenvolvidas há mais de 30 anos. Uma quantidade relativamente pequena de empresas, porém, crescente, utiliza em seus processos produtivos tecnologias mais atuais, como sistemas semiautomáticos de carga e descarga e fornos túneis (BRASIL, 2007). Geralmente, estas empresas estão localizadas na proximidade das jazidas, em função do volume de matéria-prima processada e da necessidade de transporte desse grande volume e peso, e na proximidade dos mercados consumidores. O raio médio de ação para envio dos produtos acabados gira em torno de $250 \mathrm{~km}$, a partir do qual, em situações normais, o transporte fica inviável. Para as telhas, de forma geral, o alcance pode ser maior, podendo o raio chegar aos $500 \mathrm{~km}$ em função deste produto possuir maior valor agregado. Pode haver casos, inclusive, do raio de transporte chegar até $700 \mathrm{~km}$ no caso de telhas especiais (BUSTAMANTE; BRESSIANI, 2000).

Como os produtos são comercializados geralmente nas proximidades das empresas, os estados com maior população e consequente demanda são também os maiores produtores. Neste contexto, o Estado de São Paulo é o maior produtor nacional, conta com aproximadamente 600 empresas e sua produção equivale a $21 \%$ do total nacional. A Figura 1 apresenta a distribuição dos nove principais polos de produção de cerâmica vermelha no Estado de São Paulo, sendo: ItuCampinas (1), Santa Gertrudes - Cordeirópolis (2), Tatuí - Sorocaba (3), Tambaú - Vargem Grande Sul (4), Mogi Guaçu - Itapira (5), Panorama - Paulicéia (6), José Bonifácio - Avaiandava (7), Barra Bonita Bariri (8), Ourinhos - Palmital (9) (SEBRAE, 2008). 


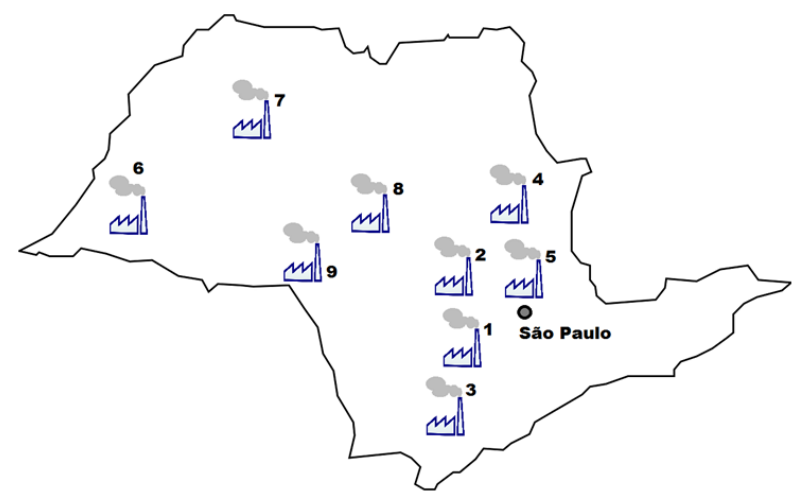

FIGURA 1: Principais polos de cerâmica vermelha no Estado de São Paulo (Fonte: Modificado de Google Map Maker, 2011).

FIGURE 1: Most important red ceramic industry conglomerates in the State of Sao Paulo.

O presente estudo teve por objetivo geral realizar sondagens sobre o uso de resíduos madeireiros parafins energéticos, emuma abordagem junto a um polo de produção de cerâmicas vermelhas do Estado de São Paulo. O levantamento envolveu a quantificação, por amostragem, da participação dos resíduos madeireiros como fonte de geração de energia no setor. Foram também analisados aspectos estratégicos ligados à oferta e consumo dos resíduos para fins energéticos no setor.

\section{MATERIAIS E MÉTODOS}

Para o diagnóstico do setor de cerâmica no Estado de São Paulo, foi realizado um levantamento junto a empresas que o compõem, utilizando a base de dados das organizações representativas do setor, tais como associações e sindicatos. A primeira instituição consultada foi o Sindicato da Indústria da Cerâmica para Construção do Estado de São Paulo (SINDICERCON-SP), do qual participam as duas principais associações ceramistas do Estado: a Associação das Cerâmicas de Tatuí e Região (ACERTAR) e a Associação das Cerâmicas Vermelhas de Itu e Região (ACERVIR). Ambas concentram 27 e 57 cerâmicas associadas, respectivamente, ou seja, aproximadamente $15 \%$ de todo o estado (dados obtidos via comunicação pessoal com as associações).

Visando a um melhor entendimento do perfil das empresas cerâmicas, foi utilizada a classificação elaborada por Santos (2003) a partir do consumo de argila e do volume de produção:

- Microempresa: consome até $150 \mathrm{~m}^{3} / \mathrm{mês}$ de argila e produz até 100 mil peças;

- Pequena empresa: consome entre 150 e $700 \mathrm{~m}^{3} / \mathrm{mês}$ de argila e produz entre 100 e $300 \mathrm{mil}$ peças;

- Média: consome entre 700 e $1.000 \mathrm{~m}^{3} / \mathrm{mês}$ de argila e produz entre 300 e 800 mil peças;

- Grande: consome mais de $1.000 \mathrm{~m}^{3} / \mathrm{mês}$ de argila e produz acima de 800 mil peças.

Para a seleção dos empreendimentos que participariam diretamente da pesquisa, foram definidos alguns pré-requisitos, tais como:

- Porte e escala de produção: a amostragem se concentrou em empreendimentos com produção mensal variando entre 300 e 800 mil peças, categoria de médias empresas, e acima de 800 mil peças, categoria de grandes empresas. Estas são as categorias mais representativas do setor e que concentram o maior número de empresas de cerâmicas vermelhas do Estado (SEBRAE, 2008).

- Tipo de combustível utilizado para produção de energia térmica em fornos: foram amostradas as cerâmicas vermelhas que não utilizavam lenha (madeira na forma de toras ou toretes) como fonte de energia térmica, mas sim cavacos de serrarias, serragem, resíduos de indústrias moveleiras, resíduos madeireiros de construção civil e cavacos provenientes do processamento de demais resíduos madeireiros.

Foram realizadas visitas às empresas para uma entrevista inicial e solicitação de manifestações de interesse em participar da pesquisa. Do total de empresas visitadas, 12 foram definidas como parceiras, pois compunham o perfil pretendido. Estas se encontram distribuídas em áreas rurais dos municípios de Monte Mor, Elias Fausto, Piracicaba, Saltinho e Tatuí, situados na região leste do Estado de São Paulo.

As informações referentes à caracterização dos empreendimentos analisados foram obtidas por meio de dados secundários, em âmbito nacional e regional, com foco no mercado interno. Além das fontes secundárias, foram levantados dados primários mediante a aplicação de questionários em entrevistas com os responsáveis pelas empresas, tendo por objetivo reunir informações sobre os aspectos técnicos e econômicos relacionados à biomassa utilizada para geração de energia. 


\section{RESULTADOS E DISCUSSÃO}

Conforme consulta junto às associações de ceramistas, a biomassa em forma de cavacos de madeira vem sendo utilizada atualmente por cerca de $80 \%$ das cerâmicas de porte médio no Estado de São Paulo, o que representa, de forma bastante significativa, a realidade energética do setor. A opção por esse tipo de biomassa, segundo as associações entrevistadas, se deve a quatro razões principais: a) disponibilidade crescente desse material para aquisição no mercado; b) melhoria ambiental, uma vez que se trata de um resíduo industrial ou material de origem renovável; c) garantia de maior homogeneidade na combustão, quando comparado com a lenha, em função do menor tamanho das partículas que o compõem e d) possibilidade de automatização da alimentação das fornalhas. Estes dois últimos aspectos indicam uma tendência estadual de substituição gradativa da lenha - tradicionalmente usada e carregada manualmente - por cavacos, com a carga das fornalhas sendo feita por meio de esteiras rolantes. Neste contexto, as cerâmicas paulistas de porte médio e grande praticamente abandonaram o uso da lenha em toretes ou "metrinho" - denominação muito conhecida no setor para indicar os toretes que medem um metro de comprimento.

A Tabela 1 apresenta os principais resultados obtidos a partir da aplicação dos questionários junto a empresas cerâmicas vermelhas no interior do Estado de São Paulo.

Duas das cerâmicas participantes da pesquisa, classificadas como de médio porte, ainda contam com sistema híbrido, sendo que alguns dos fornos ainda são alimentados com toretes, mas elas vêm trabalhando para deixar todos os fornos aptos a também queimarem cavacos em suas fornalhas.

O raio médio de distância que os cavacos percorrem desde a sua origem até a cerâmica é de aproximadamente $200 \mathrm{~km}$. Cerca de $60 \%$ destes cavacos provêm de polos madeireiros localizados dentro dessa faixa média de distância, como as regiões sul do Estado de São Paulo (cidades de Buri, Itapeva, Capão Bonito e Itararé), norte pioneiro do Estado do Paraná (Arapoti, Jaguariaíva e Sengés) e sul de Minas Gerais (Extrema e Camanducaia). De acordo com Queiroz e Barrichelo (2007), essas regiões são consideradas o berço dos reflorestamentos com pinus e eucalipto no Brasil, plantados no início do século XX para produção de madeira para ferrovias e para as primeiras indústrias de celulose e papel. Até hoje são regiões que concentram grandes áreas de reflorestamentos

TABELA 1: Resultados obtidos junto a cerâmicas vermelhas no interior do Estado de São Paulo.

TABLE 1: Results obtained from red ceramic plants in the interior of the State of Sao Paulo.

\begin{tabular}{|c|c|c|c|c|c|c|}
\hline Localização & $\begin{array}{l}\text { Produção mensal } \\
\quad \text { (mil peças) }\end{array}$ & $\begin{array}{c}\text { Consumo de } \\
\text { cavacos } \\
\left(\mathrm{m}^{3} / \mathrm{mês}\right) \\
\end{array}$ & $\begin{array}{c}\text { Eficiência } \\
\left(\mathrm{m}^{3} \text { cavaco / }\right. \\
\text { mil peças })\end{array}$ & $\begin{array}{l}\text { Raio médio } \\
\text { de origem do } \\
\text { cavaco }(\mathrm{km})\end{array}$ & $\begin{array}{l}\text { Preço médio } \\
\quad\left(\mathrm{R} \$ / \mathrm{m}^{3}\right)\end{array}$ & $\begin{array}{l}\text { Alimentação } \\
\text { dos fornos } \\
\text { com cavacos }\end{array}$ \\
\hline Saltinho & 300 & 450 & 1,5 & 150 & 45,00 & Manual \\
\hline Saltinho & 600 & 700 & 1,2 & 200 & 45,00 & Mecanizada \\
\hline Piracicaba & 500 & 700 & 1,4 & 220 & 42,00 & Manual \\
\hline Monte Mor & 1.500 & 2.000 & 1,3 & 230 & 50,00 & Mecanizada \\
\hline Monte Mor & 1.000 & 1.500 & 1,5 & 350 & 43,00 & Mecanizada \\
\hline Monte Mor & 2.000 & 2.800 & 1,4 & 200 & 40,00 & Mista \\
\hline Elias Fausto & 1.700 & 2.700 & 1,6 & 230 & 48,00 & Mecanizada \\
\hline Tatuí & 1.600 & 2.300 & 1,4 & 200 & 42,00 & Mecanizada \\
\hline Tatuí & 3.000 & 4.000 & 1,3 & 150 & 40,00 & Mecanizada \\
\hline Tatuí & 3.000 & 4.200 & 1,4 & 150 & 40,00 & Mecanizada \\
\hline Tatuí & 2.000 & 3.000 & 1,5 & 180 & 45,00 & Mecanizada \\
\hline Tatuí & 1.800 & 2.700 & 1,5 & 120 & 40,00 & Mecanizada \\
\hline Média & 1.583 & 2.254 & 1,4 & 198 & 43,00 & - \\
\hline Erro Padrão & 266 & 373 & 0,03 & 18 & 1,01 & - \\
\hline
\end{tabular}


que geram madeira para indústrias de painéis, papel e celulose, mas que também abastecem as serrarias da região com toras de diâmetros maiores. Essas serrarias acabam gerando, como subproduto, resíduos provenientes do processamento de toras de pinus e eucalipto, que são picados e transformados em cavacos. Esses cavacos são comercializados por intermediários, que têm o segmento das cerâmicas como importante consumidor.

Além dos resíduos de serrarias, foram encontrados cavacos originados de resíduos lenhosos resultantes das operações da colheita florestal de pinus e eucalipto. Esses resíduos geralmente são deixados no campo por não possuírem aproveitamento, como galhos e ramos, parte superior da árvore, partes quebradas da árvore e toretes que não atingem dimensões mínimas de uso, cujo valor comercial é insuficiente para justificar sua remoção pelas empresas de painéis, papel e celulose (PINCELLI, 2011). Esse material normalmente é vendido para empresas de "residueiros" que coletam, processam e comercializam esse material. Pincelli (2011) aponta que os resíduos lenhosos resultantes da colheita mecanizada de toras de Eucalyptus grandis com diâmetro acima de $6 \mathrm{~cm}$, em sistema de colheita mecanizada, correspondem a cerca de 16,2 $\mathrm{m}^{3}$ por hectare, o que equivale a aproximadamente $4,5 \%$ do total de madeira produzido. Nolasco (1997), estudando a exploração de toras de caixeta (Tabebuia cassinoides) com diâmetro mínimo de $12 \mathrm{~cm}$, no Estado de São Paulo, apresentou uma estimativa de que apenas $33 \%$ da madeira teriam sido aproveitados para fins comerciais. Estes trabalhos permitem inferir que a colheita florestal é geradora de uma quantidade considerável de resíduos lenhosos, passíveis de suprir as demandas industriais de biomassa para fins energéticos.

Além dos resíduos de serrarias e da exploração florestal, os $40 \%$ restantes provêm principalmente de grandes centros urbanos, como as cidades de São Paulo, Campinas, Sorocaba, Jundiaí, Piracicaba, dentre outras. São resíduos originados da poda de arborização urbana e da reciclagem de produtos madeireiros em geral, dispostos em lixões, em caçambas que recolhem entulhos, dentre outros.

Torres-Filho (2005), analisando dados do SINDUSCON (Sindicato da Indústria da Construção Civil), estima que mais de um terço da madeira utilizada nas obras da construção civil transformase em resíduo, ao final dos trabalhos. O mesmo autor aponta as indústrias de transformação, não só as unidades industriais associadas ao segmento da madeira, mas a maioria das indústrias, como outra importante fonte geradora de resíduos madeireiros, que possuem em seus inventários um controle da taxa de geração dos resíduos de madeira. Embalagens de equipamentos, paletes usados, descartes de peças, estrados, são armazenados transitoriamente nos depósitos dessas unidades, para posterior descarte.

Todas as cerâmicas avaliadas compram os cavacos de fornecedores, ou seja, nenhuma delas produz seu próprio cavaco, pelo qual pagam um preço médio que gira em torno de $\mathrm{R} \$ 43,00$ por $\mathrm{m}^{3}$ a granel, preço CIF, ou seja, preço do material já transportado e colocado no pátio da cerâmica. São várias as empresas que oferecem esse tipo de produto nas regiões de estudo. Os preços médios foram obtidos por meio de informações junto às próprias cerâmicas e por contatos com fornecedores via telefone ou internet. Conforme observado na Tabela 1, o mercado da região não costuma abater os preços dos cavacos em função da escala de compra, uma vez que não houve correlação entre a quantidade consumida e os preços pagos pelos cavacos.

Nenhuma das empresas participantes da pesquisa realizou algum tipo de tratamento aos cavacos antes de queimá-los nas fornalhas. Os cavacos são depositados em pátios cobertos e são misturados com aqueles remanescentes de outras cargas. O volume de estoque de cavacos nos pátios é muito variável e depende muito do porte e do poder aquisitivo da empresa, sendo que, em média, podem ser suficientes para suprir as cerâmicas por um período que varia de uma a duas semanas de produção. Pesam, nessa variável, o fator custo e o espaço disponível para estocagem.

Para as empresas avaliadas, a temperatura máxima exigida nos fornos é da ordem de $900^{\circ} \mathrm{C}$ e a eficiência média apurada foi de $1,4 \mathrm{~m}^{3}$ de cavaco para cada milheiro de peças acabadas produzidas. Algumas empresas informaram a sua produção em toneladas de produtos acabados por mês. Nesses casos, a conversão para milheiros de peças foi feito com base no cálculo de que cada peça de cerâmica vermelha pesa em média $2 \mathrm{~kg}$ (SEBRAE, 2008). A eficiência média relatada pode ser considerada média/baixa, compatível com a performance obtida em fornos do tipo "abóbada/redondo" e "câmaras", de acordo com a classificação apresentada por Henriques Junior, Schwob e Rodrigues (2013). Este é um indicativo de que existe oportunidade para melhorias nas tecnologias de combustão utilizadas na região avaliada. 
Como pergunta final do questionário aplicado aos ceramistas, solicitou-se que eles descrevessem quais características que mais interferem para uma queima mais eficiente do cavaco no seu processo produtivo. A resposta unânime foi a necessidade de maior constância na qualidade do material, tanto para o tipo de madeira que compõe os cavacos, quanto para a umidade do material e a sua heterogeneidade, que normalmente variam a cada carga recebida.

\section{CONCLUSÕES}

A biomassa em forma de cavacos de madeira vem sendo utilizada atualmente por cerca de $80 \%$ das cerâmicas de porte médio no Estado de São Paulo. A opção por esse tipo de biomassa se deve a quatro razões principais: a) disponibilidade crescente desse material; b) vantagens ambientais; c) garantia de maior homogeneidade na combustão, quando comparado com a lenha e d) possibilidade de automatização da alimentação das fornalhas.

Os cavacos são originados de resíduos de serrarias, resíduos lenhosos das operações da colheita florestal de pinus e eucalipto, além de resíduos da poda de arborização urbana e da reciclagem de produtos madeireiros em geral.

O raio médio de distância que os cavacos percorrem desde a sua origem até as cerâmicas é de aproximadamente $200 \mathrm{~km}$. Todas as cerâmicas avaliadas compram os cavacos de terceiros, ou seja, nenhuma delas produz seu próprio cavaco, pelo qual pagam um preço médio que gira em torno de $\mathrm{R} \$$ 43,00 por $\mathrm{m}^{3}$ a granel. A eficiência média apurada foi de $1,4 \mathrm{~m}^{3}$ de cavaco para cada milheiro de peças acabadas produzidas.

As empresas entrevistadas expressaram a necessidade de maior regularidade na qualidade do biocombustível, tanto para o tipo de madeira que compõe os cavacos, quanto para a umidade do material e a sua heterogeneidade, que normalmente variam a cada carga recebida.

\section{REFERÊNCIAS BIBLIOGRÁFICAS}

ASSOCIAÇÃO BRASILEIRA DE CERÂMICAS. Informações técnicas: processo de fabricação de cerâmica vermelha. 2011. Disponível em: $<$ http: http://www.abceram.org.br/site/?area $=45>$. Acesso em: 8 mar. 2011.

ASSOCIAÇÃO NACIONAL DA INDÚSTRIA CERÂMICA. Site institucional. Rio de Janeiro.
Disponível em: $\quad<$ http://www.anicer.com.br/>. Acesso em: 17 mar. 2007.

BACCELLI JÚNIOR, G. Avaliação do processo industrial da cerâmica vermelha na região do Sérido - RN. 2010. 201 f. Tese (Doutorado em Engenharia Mecânica) - Departamento de Engenharia Mecânica, Universidade Federal do Rio Grande do Norte, 2010.

BRASIL. Ministério do Desenvolvimento, Indústria e Comércio Exterior. Plano de Desenvolvimento do Arranjo Produtivo Local de Cerâmica Vermelha de Tambaú - SP. Brasília: Ministério do Desenvolvimento, Indústria e Comércio Exterior, 2007. 73 p.

BRITO, J. O. O uso energético da madeira. Estudos Avançados, São Paulo, v. 21, n. 59, p. 1-9, 2007.

et al. Chemical composition changes in Eucalyptus and Pinus woods submitted to heat treatment. Bioresource Technology, Essex, v. 99, n. 18 , p. 8545-8548, 2008.

BUSTAMANTE, G.; BRESSIANI, J. C. A indústria cerâmica brasileira. Cerâmica Industrial, São Paulo, v. 5, n. 3, 2000.

EMPRESA DE PESQUISA ENERGÉTICA. Balanço Energético Nacional 2011: ano base 2010. [s. 1.]: EPE, 2011. Disponível em: $<$ https://ben. epe.gov.br/downloads/Relatorio_Final_BEN_2011. pdf. $>$. Acesso em: 26 out. 2011.

HENRIQUES JUNIOR, M. F.; SCHWOB, M. R. V.; RODRIGUES, J. A. P. Manual de eficiência energética na indústria de cerâmica vermelha. Rio de Janeiro: INT/MCTI, 2013. 28 p.

NOLASCO, A. M. Análise quantitativa dos resíduos da extração e processamento da caixeta (Tabebuia cassinoides) no Vale do Ribeira-SP. In: WORKSHOP SULAMERICANO SOBRE USOS ALTERNATIVOS DE RESÍDUOS DE ORIGEM FLORESTAL E URBANA, 1997, Curitiba. Anais... Curitiba: Embrapa Florestas, 1997. p. 113-116.

PINCELLI, A. L. P. S. M. Características dos resíduos da colheita de madeira de eucalipto e pinus, submetidos ao tratamento térmico, com foco na aplicação energética. 2011. $127 \mathrm{f}$. Tese (Doutorado em Recursos Florestais) - Escola Superior de Agricultura Luiz de Queiroz, ESALQ/ USP, 2011.

QUEIROZ, L. R. S.; BARRICHELO, L. E. G. O eucalipto: um século no Brasil $=$ The eucalypt: a century in Brazil. [s. 1.]: Duratex, 2007, 131 p. Disponível em: <http://www.celso-foelkel.com. br/artigos/outros/O\%20Eucalipto_Duratex.pdf $>$. Acesso em: 12 fev. 2010. 
SANTOS, C. S. A indústria cerâmica em Barra Bonita (SP) e suas relações com a usina hidrelétrica de Bariri: panorama e perspectiva. 2003. 78 f. Dissertação (Mestrado em Geociências, Área de administração e política de Recursos Minerais) - Instituto de Geociências, Universidade Estadual de Campinas - UNICAMP, Campinas, 2003.

SÃO PAULO (Estado). Secretaria de Energia, Recursos Hídricos e Saneamento. Balanço Energético do Estado de São Paulo 2011: ano base 2010. São Paulo: Secretaria de Energia, 2011. $264 \mathrm{p}$.

SEBRAE. Cerâmica vermelha: estudo de mercado. Brasília: Ed. SEBRAE, 2008. 41 p.
SÜFFERT, R. L.; BAJAY, S. V.; LIMA, C. R. Energia, sociedade e desenvolvimento sustentável: o caso da reposição de florestas plantadas no Rio Grande do Sul. [2005]. Disponível em: <http://www.aondevamos. eng.br/verdade/ artigos/enersoc.htm>. Acesso em: 3 dez. 2005.

TORRES-FILHO, A. Viabilidade Técnica e Ambiental da Utilização de Resíduos de Madeira para a Produção de um Combustível Alternativo. 2005. 122 f. Dissertação (Mestrado em Saneamento, Meio Ambiente e Recursos Hídricos) - Programa de Pós-Graduação em Saneamento, Meio Ambiente e Recursos Hídricos, Escola de Engenharia da Universidade Federal de Minas Gerais, 2005. 